\title{
Estimation of the effect of long-range transport on seasonal variation of aerosols over northeastern India
}

\author{
M. M. Gogoi ${ }^{1}$, P. K. Bhuyan ${ }^{2}$, and K. Krishna Moorthy ${ }^{1}$ \\ ${ }^{1}$ SPL, VSSC, Trivandrum 695022 India \\ ${ }^{2}$ Department of Physics, Dibrugarh University, Dibrugarh 786004 India
}

Received: 9 February 2007 - Revised: 18 February 2008 - Accepted: 13 March 2008 - Published: 11 June 2008

\begin{abstract}
Spectral aerosol optical depth (AOD) at ten discrete channels in the visible and near IR regions were estimated over Dibrugarh, located in the northeastern part of India, using a ground-based multi-wavelength solar radiometer (MWR) from October 2001 to February 2006. The observations reveal seasonal variations with low values of AODs in retreating monsoon and high values in the pre-monsoon season. Generally the AODs are high at shorter wavelengths and low at longer wavelengths. AOD spectra are relatively steep in winter compared to that in the monsoon period. The average value of AOD lies between $0.44 \pm 0.07$ and $0.56 \pm 0.07$ at $500 \mathrm{~nm}$ during the pre-monsoon season and between $0.19 \pm 0.02$ and $0.22 \pm 0.02$ during re-treating monsoon at the same wavelength. Comparison of MWR observation on Dibrugarh with satellite (MODIS) observation indicates a good correspondence between ground-based and satellite derived AODs. The synoptic wind pattern obtained from National Centre for Medium Range Weather Forecasting (NCMRWF), India and back trajectory analysis using the NOAA Hybrid Single-Particle Lagrangian Integrated Trajectory (HYSPLIT4) Model indicates that maximum contribution to aerosol extinction could be due to transport of pollutants from the industrialized and urban regions of India and large amounts of desert and mineral aerosols from the west Asian and Indian desert. Equal contributions from Bay-ofBengal (BoB), in addition to that from the Indian landmass and west Asian desert leads to a further increase of AOD over the region of interest in the pre-monsoon seasons.
\end{abstract}

Keywords. Atmospheric composition and structure (Aerosols and particles; Pollution - urban and regional; Instruments and techniques)

Correspondence to: P. K. Bhuyan

(pkbhuyan@gmail.com)

\section{Introduction}

Although a trace species by volume, aerosols produce significant atmospheric effects that have a direct bearing on dayto-day life as well as a long-term impact on the climate and hence the Geosphere-Biosphere system. They produce a direct effect on human health, visibility, air quality, and environment and also lead to the formation of dew, mist and fog. Besides the above-mentioned effects, the importance of atmospheric aerosols is being increasingly recognized in recent years in the regional and global (direct and indirect) radiative forcing and the resulting climatic implications (e.g. Charlson et al., 1991, 1992).

In assessing the radiative forcing of atmospheric aerosols at a given location, from the standpoint of climatic impact, the aerosol parameter of utmost importance is the columnar spectral aerosol optical depth (AOD, denoted as $\tau_{p \lambda}$ ) and its variation in the spectral domain. It is related to several physical properties of the aerosols through the relation (King et al., 1982)

$\tau_{p \lambda}=\int_{0}^{z} \int_{r_{1}}^{r_{2}} \pi r^{2} Q_{e x}, n(r, z) d r d z$

where $Q_{e x}$ is the Mie extinction efficiency parameter, which is a function of particle size in relation to the wavelength of the radiation, and its complex refractive index. The integration is over the atmospheric column from ground to the region where the aerosol abundance is significant (troposphere) and over the size range, which contributes significantly to $Q_{e x}$ and is usually known as optically active size range $(0.05$ to $5 \mu \mathrm{m})$. Thus the spectral AOD depends on the columnar abundance, size distribution and components of the aerosols. As such, the AODs will respond to changes in source strengths, aerosol microphysics and removal mechanisms, such as precipitation and cloud cycling (e.g. Suzuki and Tsunogai, 1988; Moorthy et al., 1991; Smirnov et al.,

Published by Copernicus Publications on behalf of the European Geosciences Union. 


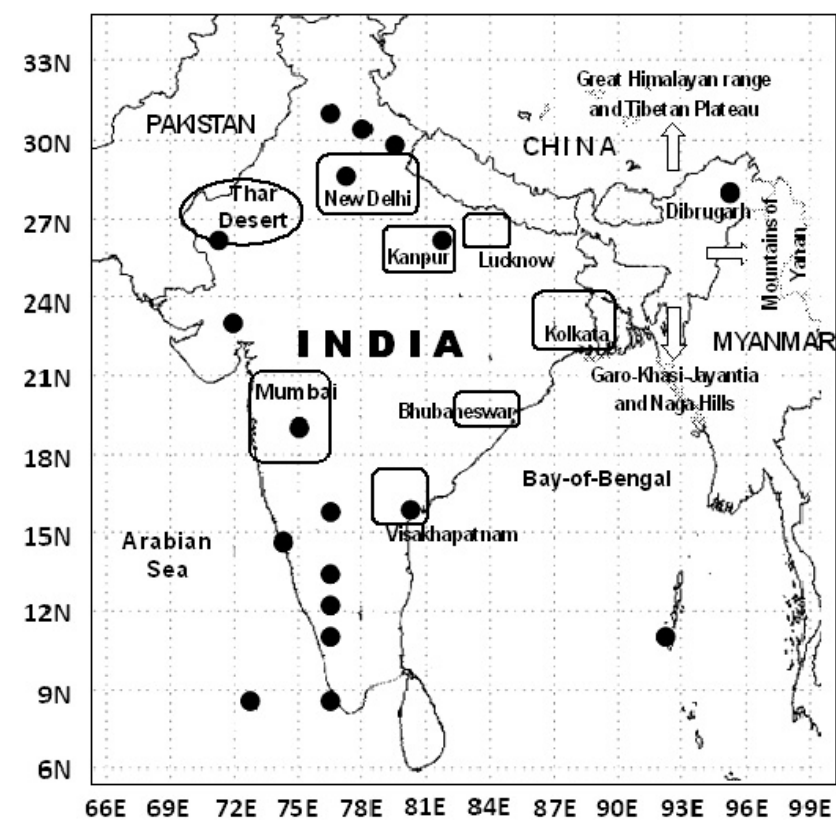

Fig. 1. Ground-based MWR observatories (black dots) over the Indian mainland and the prominent Industrial regions (squares) along the Ganga basin, western India and the peninsular region of the Bayof-Bengal. The ellipse represents the Thar Desert area.

1994; Saha and Moorthy, 2004) and to long distant transport, which occurs at higher levels in the atmosphere (e.g. Moorthy et al., 2003). Thus regional characterization of spectral AOD is of great importance and relevance in understanding the radiative impact of aerosols.

In recent years there has been a concerted effort to characterize aerosols over the Indian region, which has a vast continental landmass with heterogeneous properties. Individual measurements (e.g. Moorthy et al., 1988, 1989; Jayaraman et al., 1993; Satheesh et al., 2001; Devara et al, 2001; Sharma et al., 2003; Suresh et al., 2005, Moorthy et al., 1993, 1998; Niranjan et al., 2004; Sagar et al., 2004; Bhuyan et al., 2005 etc.) and coordinated field campaigns, such as the INDOEX (e.g. Satheesh et al., 1999; Ramanathan et al., 2001), the field campaign under Indian Space Research Organization's Geosphere Biosphere Program (ISRO-GBP) (e.g. Moorthy et al., 2005) have greatly added to our knowledge on the aerosol characteristics over this region.

The Multiwavelength Solar Radiometer (MWR) at Dibrugarh has broadened the database for the existing network of the "Aerosol Climatology and Effect" project as part of ISRO-GBP.

\section{Location, data and analysis}

Dibrugarh $\left(27.3^{\circ} \mathrm{N}, 94.6^{\circ} \mathrm{E}, 111 \mathrm{~m}\right.$ a.m.s.l. $)$ is located close to the northeastern boundary of India, in the northeastern corner of the upper Brahmaputra valley (Fig. 1). The val- ley is surrounded by the great Himalayan range and Tibetan Plateau to the north, Garo-Khasi-Jayantia and Naga hills to the south and mountains of Yanan to the east, but is open to the west side towards the Gangetic plain of India. Thus, the westerly winds play a dominant role in transporting the suspended particulate matters from west Asia, across the east and then passing over the Indian landmass towards Brahmaputra valley. The major industrial and urban regions of India are shown in Fig. 1 (Tripathi et al., 2005; Vinoj et al., 2004). Most of the westerly upper air flow trajectories pass across these regions of India before entering the Brahmaputra valley.

The MWR at Dibrugarh is operated from the rooftop of the building of the Physics Department of Dibrugarh University ( $\sim 8 \mathrm{~m}$ above ground level) on all days when unobscured solar visibility is available for at least 2 to $3 \mathrm{~h}$. Dibrugarh is endowed with extensive water resources and surrounded by lush green tea plantations around it. No significant local pollution sources are present in the proximity of the site, except the vehicle exhausts of the national highway running through the university campus. On the basis of the climatic characteristics, such as distribution of temperature, rainfall, rainy days, humidity, presence of fog and thunderstorms, the climate of the area may be classified into four seasons: (a) winter - W, (b) pre-monsoon or summer - S, (c) monsoon - M1 and (d) retreating monsoon - M2. December, January and February are the winter months. The months of March, April and May constitute the pre-monsoon season. June, July, August and September are the monsoon months and the months of October and November represent the retreating monsoon season. The average annual rainfall of $\mathrm{Di}$ brugarh city is $276 \mathrm{~cm}$ with a total number of 193 rainy days. The annual mean temperature is $23.9^{\circ} \mathrm{C}$.

In this study, the contribution of long-range transport to the growth or decay of aerosol extinction over the northeast Indian location Dibrugarh is being investigated using the MWR data at Dibrugarh from October 2001 to February 2006, MODIS (on board the Terra platform) derived AOD, and wind and back trajectory analysis from NCMRWF and HYSPLIT, respectively.

The National Centre for Medium Range Weather Forecasting (NCMRWF) is the premier institution in India that provides Medium Range Weather Forecasts through deterministic methods and renders Agro Advisory Services (AAS) to the farmers.

The ground-based passive multi-wavelength solar radiometer (MWR), used to retrieve aerosol optical depth over Dibrugarh, was designed and developed at Space Physics Laboratory (SPL), Vikram Sarabhai Space Centre, Trivandrum, following the principle of filter wheel radiometry, as described by Shaw et al. (1973). The instrument provides columnar total optical depth at ten discrete narrow wavelength bands (FWHM of 5 to $6 \mathrm{~nm}$ at different wavelengths) centered at $380,400,450,500,600,650,750,850$, 935 and $1025 \mathrm{~nm}$ by making continuous spectral extinction 
measurements of directly transmitted solar radiation as a function of solar zenith angle.

Following Lambert-Beer law, the directly transmitted ground reaching solar flux $F_{\lambda}$ at a monochromatic wavelength $\lambda$ is given by

$F_{\lambda}=F_{o \lambda}\left(\frac{R_{o}}{R}\right)^{2} \exp \left(-\tau_{\lambda} m\right)$

where $R_{o}$ and $R$ represents the mean and instantaneous SunEarth distance, $F_{o \lambda}$ is the extra-terrestrial solar flux at $\lambda, \tau_{\lambda}$ is the total columnar optical depth of the atmosphere and $m$ is the relative air mass (a geometrical term to account for the relative increase in optical path length with increase in solar zenith angle).

In MWR, the output $V_{\lambda}$ is directly proportional to the incident solar radiation. This in turn is proportional to $F_{\lambda}$, therefore Eq. (2) can be expressed as

$V_{\lambda}=V_{o \lambda}\left(\frac{R_{o}}{R}\right)^{2} \exp \left(-\tau_{\lambda} m\right)$

where $V_{o \lambda}$ represents the system output corresponding to $\left(F_{O \lambda}\right)$. Taking logarithms on both sides of Eq. (3),

$\ln V_{\lambda}=\left[\ln V_{o \lambda}+2 \ln \left(\frac{R_{o}}{R}\right)\right]-\tau_{\lambda} m$.

Equation (4) represents a linear relation between the natural logarithm of the MWR output $V_{\lambda}$ and relative air mass $m$. A plot of $\ln \left(V_{\lambda}\right)$ against $m$ during periods when $\tau_{\lambda}$ remains invariant yields a straight line with a slope equal to $\tau_{\lambda}$ and a Y-intercept for $m=0$ (known as the zero airmass intercept) equal to the term inside the bracket which after correcting for the Sun-Earth distance gives $\left[\ln \left(V_{o \lambda}\right)\right]$. Since $V_{o \lambda}$ is proportional to $F_{o \lambda}$, which remains invariant over years, any change in zero airmass intercept (during clear periods) should arise from variations in the MWR parameters. The long-term temporal stability of the Langley intercept, corrected for the daily variation of the Sun-Earth distance was used as an indirect calibration of the instrument. During the study period, the long-term stability of the instrument was fairly good, with the Langley intercept lying within $10 \%$ of the mean for the worst cases. A very few days, when a significant deviation was observed, were not considered in the further analysis. As the performance of the interference filters deteriorate, there will be a very long-term trend in the mean corrected intercept and this information was used to replace the filters whenever serious deterioration was detected. Otherwise the entire filter set was changed after a period of 3 years.

In analyzing the MWR data, the data collected during the forenoon (FN) and/or afternoon (AN) parts of the day were considered as a single data set and the average spectral AODs were retrieved for that data set following the Langley plot technique and the total columnar optical depth $\tau_{\lambda}$, the corrected zero airmass intercept (also called Langley intercept), the mean variance $\sigma_{\tau}^{2}$ of the slope $\tau_{\lambda}$ and the correlation coefficient $\rho$ between $\ln \left(V_{\lambda}\right)$ and $m$ are determined.

The total optical depth is the sum of the contributions due to molecular scattering $\left(\tau_{m \lambda}\right)$, extinction due to the aerosols $\left(\tau_{p \lambda}\right)$ and absorption due to ozone $\left(\tau_{O_{3} \lambda}\right)$ and water vapor $\left(\tau_{w \lambda}\right)$, so that,

$\tau_{\lambda}=\tau_{m \lambda}+\tau_{p \lambda}+\tau_{O_{3} \lambda}+\tau_{w \lambda}$,

where $\tau_{p \lambda}$ can be deduced from $\tau_{\lambda}$ estimated from MWR measurements if $\tau_{m \lambda}, \tau_{O_{3} \lambda}$ and $\tau_{w \lambda}$ can be estimated separately. $\tau_{m \lambda}$ values are estimated analytically using model/reference atmosphere profiles as given by Sasi and Sengupta (1979). The values of $\tau_{m \lambda}$ at Dibrugarh are 0.432 , $0.351,0.216,0.140,0.067,0.048,0.027,0.016,0.011$ and 0.007 , respectively, at the ten wavelengths of MWR. The ozone absorption mainly contributes in the Chappius bands centered at $0.575 \mu \mathrm{m}$ (Gutiërrez-Moreno and Cortës, 1982). The significant values of $\tau_{O_{3} \lambda}$ are $0.008,0.065,0.028,0.016$ and 0.002 at wavelengths $450,500,600,650$ and $750 \mathrm{~nm}$, respectively. There is also a weak absorption by $\mathrm{NO}_{2}$ at wavelengths below $450 \mathrm{~nm}$. The typical value of optical depth due to this is 0.006 (Tomasi et al., 1985), which is quite small compared to other terms in Eq. (5) and hence not considered significant. Water vapor exhibits large variability and hence $\tau_{w \lambda}$ is estimated from the day-to-day measurements. Using the MWR measurements at $935 \mathrm{~nm}$ and $1025 \mathrm{~nm}$, the columnar water vapor content is estimated using the generalized transmission function (Leckner, 1978) and this is used to estimate the absorption at $850 \mathrm{~nm}$ (Nair et al., 1998; Bhuyan et al., 2005).

Following Russell et al. (1993), the overall error in the derivation of AOD using the Langley technique can be written as

$$
\begin{aligned}
\delta \tau_{p \lambda}= & \left(\tau_{p \lambda} \frac{\delta F}{F}\right)^{2}+\left(\tau_{\lambda} \frac{\delta m}{m}\right)^{2}+\left(\frac{1}{m} \frac{\delta V_{o \lambda}}{V_{o \lambda}}\right)^{2} \\
& +\left(\frac{1}{m} \frac{\delta V_{\lambda}}{V_{o}}\right)^{2}+\Delta \tau_{o}^{2}
\end{aligned}
$$

where

$\Delta \tau_{o}^{2}=\delta \tau_{R \lambda}^{2}+\delta \tau_{O_{3} \lambda}^{2}+\delta \tau_{N O_{2} \lambda}^{2}+\delta \tau_{w \lambda}^{2}$.

The first term on the right-hand side of Eq. (6) represents the error contributed by the diffused scatter radiation, detected by the photo-detector. The second term arises due to the errors in the computation of the relative air mass $m$, the third term represents the error arising due to the uncertainty of the zero airmass calibration output; the fourth term represents the uncertainty in reading the MWR output and the fifth term represents the total error due to the uncertainties in the optical depths due to Rayleigh scattering and absorption by $\mathrm{O}_{3}$, $\mathrm{NO}_{2}$ and water vapor.

Estimates have shown that the typical error in the retrieved value of $\tau_{p \lambda}$ lies in the range $\sim 0.009-0.011$ at different 


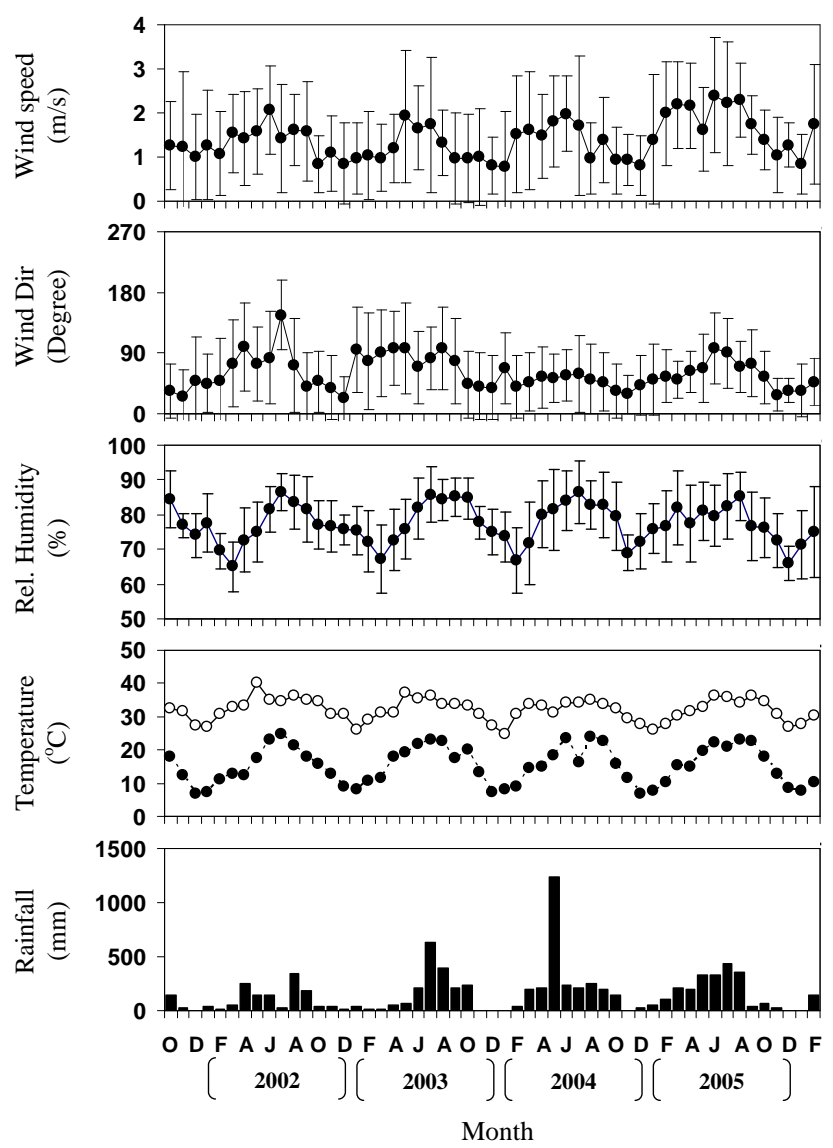

Fig. 2. Monthly variation of (a) surface wind speed (b) surface wind direction, (c) relative humidity, (d) maximum and minimum temperature and (e) monthly total rainfall, respectively, from October 2001 to February 2006. The vertical bars represent the standard errors.

wavelengths excluding the variance of the Langley fit (Moorthy et al., 1998). The small variance in the Langley intercept $(<10 \%)$ along with the other uncertainties in the estimation of $\tau_{p \lambda}$, puts the uncertainty in the range of 0.03-0.05 at different wavelengths, with the higher values at shorter wavelengths $(<500 \mathrm{~nm})$ and during high AODs $(>0.5)$. More details on the MWR, including analysis details and error budget are given in several earlier papers (Moorthy et al., 1997, 1999, 2001; Satheesh and Moorthy, 1997; Sagar et al., 2004; Saha et al., 2005).

\subsection{Back trajectory model}

Five-day three-dimensional back trajectories were calculated using the NOAA HYbrid Single-Particle Lagrangian Integrated Trajectory Model (HYSPLIT model) with the $1^{\circ} \times 1^{\circ}$ latitude-longitude grid, "final" (FNL) meteorological database (Draxler and Hess, 1997). The 6-hourly FNL archive data are generated by the NCEP GDAS (National Centers for Environmental Prediction Global Data Assimi-

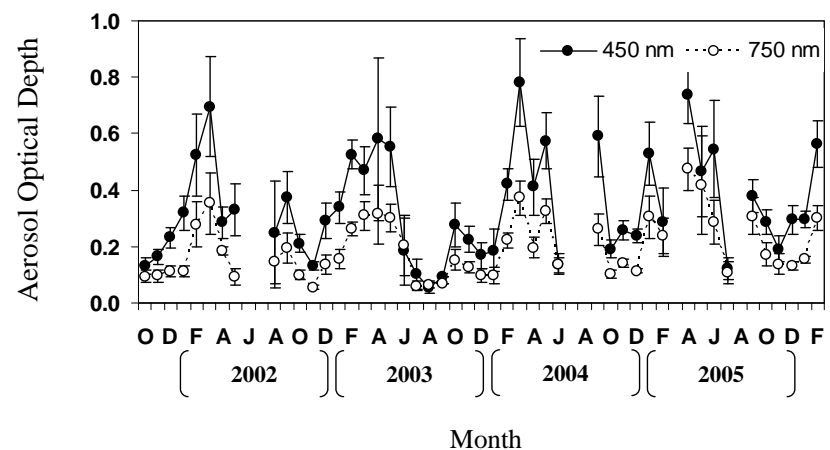

Fig. 3. Monthly variation of aerosol optical depth over Dibrugarh at $450 \mathrm{~nm}$ and $750 \mathrm{~nm}$ from October 2001 to February 2006.

lation System) wind field reanalysis. GDAS uses the spectral medium range forecast (MRF) model for the forecast. The FNL database contains basic fields, such as the $\mathrm{u}$ - and v-wind components, temperature and humidity at 13 vertical levels, from surface to $20 \mathrm{hPa}$. Further information on the FNL meteorological database can be found at http://www.arl.noaa. gov/ss/transport/archives.html (Formenti et al., 2001).

\subsection{Surface meteorological data}

The month-to-month variations of wind, temperature, relative humidity and the monthly total rainfall are shown in Fig. 2. The surface wind speeds are generally low $\left(<4 \mathrm{~ms}^{-1}\right)$ with no significant variation from month to month or season to season. However, the average values of wind speed are slightly greater during the pre-monsoon and monsoon months. The predominant surface wind direction over Dibrugarh is generally northeasterly $\left(45^{\circ}\right)$, which shifts towards easterly $\left(90^{\circ}\right)$ during the pre-monsoon and monsoon months.

Maximum and minimum daily temperature $\left(T_{\max }\right.$ and $T_{\text {min }}$ ) varies between $25^{\circ} \mathrm{C}$ to $35^{\circ} \mathrm{C}$ and $7^{\circ} \mathrm{C}$ to $25^{\circ} \mathrm{C}$, respectively. Both $T_{\max }$ and $T_{\min }$ show similar annual variation. The month of occurrence of annual maximum in temperature appears to vary from one year to another.

The average relative humidity $(\mathrm{RH})$ observed at 05:30 IST, 11:30 IST and 17:30 IST is high (>60\%), which is indicative of a tropical wet regime. Figure 2 also indicates that more than $84 \%$ of the annual rainfall occurs during April to September and about $55 \%$ of total rainfall during June to August every year.

\section{Results and discussion}

\subsection{Temporal characteristics of aerosol optical depth}

The monthly variation of the aerosol optical depth at wavelengths $450 \mathrm{~nm}$ (in the visible) and $750 \mathrm{~nm}$ (in the near IR) is shown in Fig. 3. AOD increases from February onwards and attains a peak value during the pre monsoon-months (March, 


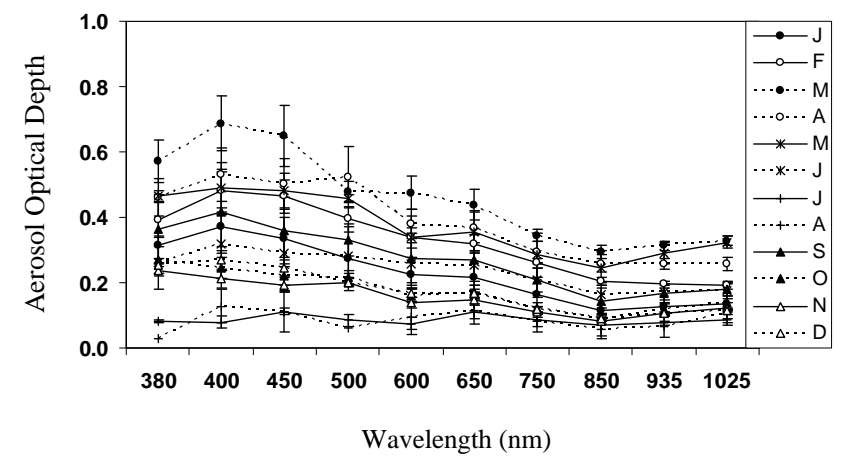

Fig. 4. Spectral variation of aerosol optical depth over Dibrugarh.

April and May). The standard deviations are generally high during the monsoon months, which indicate higher day-today variability during these months. The highest value of AOD $(\sim 0.79 \pm 0.18$ at $400 \mathrm{~nm})$ during the period of observation was observed in the month of March 2004. The AODs are lower in the retreating monsoon season except during 2003, where the lowest value of AOD occurred in a monsoon month. On a seasonal basis, the mean maximum and minimum values of AOD at $450 \mathrm{~nm}$ and $750 \mathrm{~nm}$ in the four respective seasons, combined for all years of observation, are given in Table 1. The AODs are highest in the pre-monsoon months at both long or short wavelengths and lowest in the retreating monsoon.

\subsection{Spectral characteristics of aerosol optical depth}

The spectral variation of aerosol optical depths are examined by plotting the monthly mean $\tau_{p \lambda}$ values as a function of wavelength $(\lambda)$, as shown in Fig. 4. This is shown for the mean monthly $\tau_{p \lambda}$ values irrespective of years during the entire period of observation. The average spectral temporal variations on a seasonal basis are also shown in Fig. 5 as a contour plot. In general, the wavelength dependence of $\tau_{p \lambda}$ remains nearly the same in all the years of observation. The AODs first increase from $380 \mathrm{~nm}$ to $400 \mathrm{~nm}$ and then decrease with an increase in wavelengths towards the higher end of the spectrum. There is a slight increase of AOD at $1025 \mathrm{~nm}$.

The spectral characteristics of aerosol optical depth are indicative of the size distribution of the aerosols and they clearly indicate the differences between the sizes of the particles at different months (Shaw et al., 1973). Following Ångström (1961) the wavelength variation of AOD can be expressed as $\beta \lambda^{-\alpha}$, where $\beta$ and $\alpha$ are constants. According to the Ångström formula

$\tau_{p \lambda}=\beta \lambda^{-\alpha}$,

where $\beta$ is the Ångström turbidity coefficient, equal to $\tau_{p \lambda}$ at $\lambda=1 \mu \mathrm{m}$ and $\alpha$ is the wavelength exponent. The wavelength exponent $\alpha$ is related to aerosol size distribution and

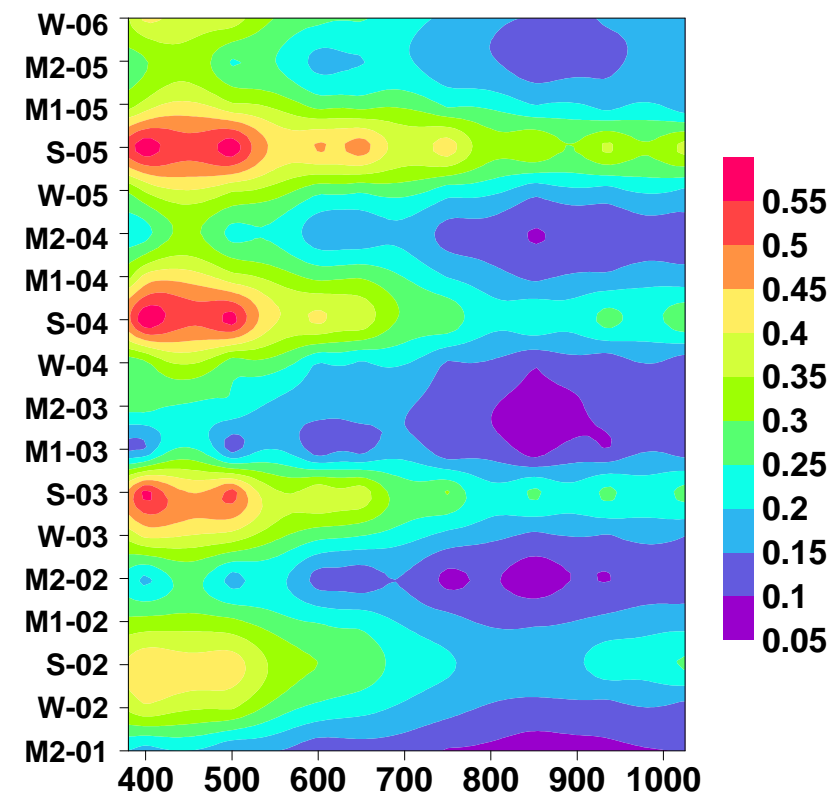

Wavelength (nm)

Fig. 5. Temporal and spectral variation of aerosol optical depth.

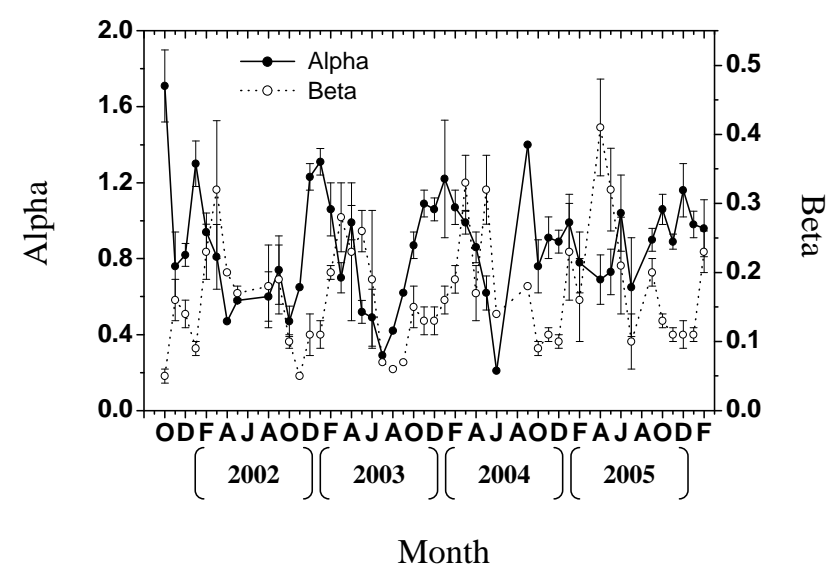

Fig. 6. Monthly variation of Ångström parameters: alpha and beta over Dibrugarh from October 2001 to February 2006.

is a measure of the relative dominance of fine, sub micron aerosols over the coarse aerosols while $\beta$ represents the total aerosols present in the atmosphere in the vertical direction. A higher value of $\alpha$ indicates a sharper aerosol size spectrum, more dominated by smaller aerosols.

Since the value of $\beta$ ( $\tau_{p \lambda}$ at $\lambda=1 \mu \mathrm{m}$ ) is a measure of the aerosol (column) loading (Tomasi et al., 1983) and depends more on large $(r>\sim 0.5 \mu \mathrm{m})$ aerosol particles, its variation with time would be indicative of the temporal variation of large particles concentration. 
Table 1. Seasonal maximum and minimum values of AOD at 450 and $750 \mathrm{~nm}$.

\begin{tabular}{lcccc}
\hline Season & $\tau_{p 450}$, Max & $\tau_{p 450}$, Min & $\tau_{p 750}$, Max & $\tau_{p 750}$, Min \\
\hline Winter & $0.56 \pm 0.08$ & $0.17 \pm 0.05$ & $0.31 \pm 0.08$ & $0.10 \pm 0.03$ \\
Premonsoon & $0.78 \pm 0.16$ & $0.29 \pm 0.06$ & $0.51 \pm 0.07$ & $0.09 \pm 0.03$ \\
Monsoon & $0.55 \pm 0.17$ & $0.15 \pm 0.02$ & $0.29 \pm 0.07$ & $0.07 \pm 0.01$ \\
Retreating-monsoon & $0.29 \pm 0.05$ & $0.13 \pm 0.02$ & $0.17 \pm 0.04$ & $0.06 \pm 0.01$ \\
\hline
\end{tabular}

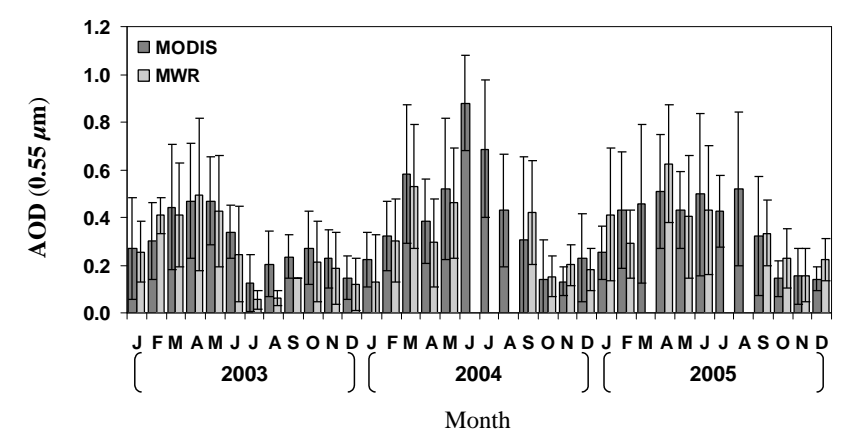

Fig. 7. Monthly averaged AOD at $0.55 \mu \mathrm{m}$ wavelength over Dibrugarh during the year 2003 to 2005 retrieved from MODIS and MWR. The error bars represent the standard deviation of AOD for that month.

In the present study, aerosol optical depth values of individual sets of observation were examined for their agreement with Eq. (8), involving a least-squares fit between $\tau_{p \lambda}$ and $\lambda$ in a log-log scale. The slope of the regression line gives the value of $\alpha$ while $\beta$ is evaluated from the intercept. In general, a good agreement with Eq. (8) is obtained in most of the cases with the correlation coefficient $\rho$ lying in the range -0.60 and -0.99 . The monthly mean values and the standard deviations of $\alpha$ and $\beta$ obtained from the respective data sets are shown in Fig. 6.

It can be seen from Fig. 6 that the average values of $\alpha$ are higher during October to April and lower during May to September. In general, $\alpha$ peaks during the months of December, January and February, indicating prominence of fine mode particles in winter. The maximum and minimum value of $\alpha$ vary between $1.71 \pm 0.19$ (October 2001) and $0.21 \pm 0.01$ (July 2003). The mean Ångström turbidity coefficient $\beta$ lies between $0.41 \pm 0.07$ (April 2005) and 0.05 \pm 0.02 (October 2001, November 2002) during the study period at the observational site. The higher values of $\beta$ seen in the months of March, April and May indicate that the total aerosol mass loading is highest during this pre-monsoon months. The values of $\beta$ are lower during the re-treating monsoon and winter months.

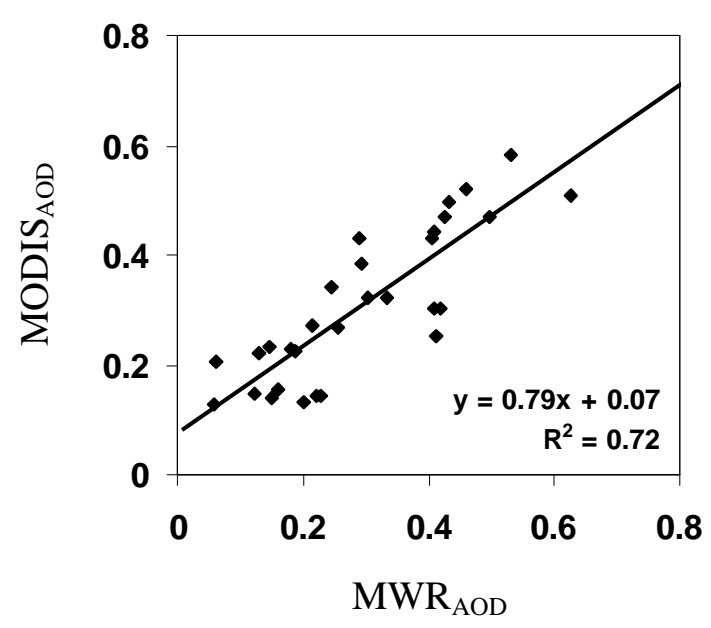

Fig. 8. Scatter plot between AOD derived from MODIS and MWR during the year 2003 to 2005 over Dibrugarh.

3.3 Comparison of aerosol optical depths from groundbased and satellite observations

The MWR observation is not adequate for obtaining aerosol characteristics for all the months in a year due to unfair weather conditions, particularly during the monsoon periods. The lack of data due to cloud cover can be compensated through use of satellite-derived observations, provided these are validated and compared with the ground-based measurements. Moreover, a single ground-based aerosol monitoring station in northeastern India is not very useful in assessing the regional distribution due to the strong spatial and temporal variability of aerosol particles. Validated satellite measurements may fill the existing data gap and provide a more homogeneous picture of the aerosol environment over this region. Moderate Resolution Imaging Spectro-Radiometer (MODIS) imparts information about global distribution of aerosols and their properties. With a view to supplement the MWR derived AOD over Dibrugarh, we have used MODIS derived AODs (Kaufman et al., 2003) on board the EOS (Earth Observing system) Terra platform at $550 \mathrm{~nm}$ and compared it with the AODs estimated using the MWR at the same wavelength. A linear interpolation technique has been used to calculate the AOD value at $550 \mathrm{~nm}$, from the available wavelengths of the MWR. 

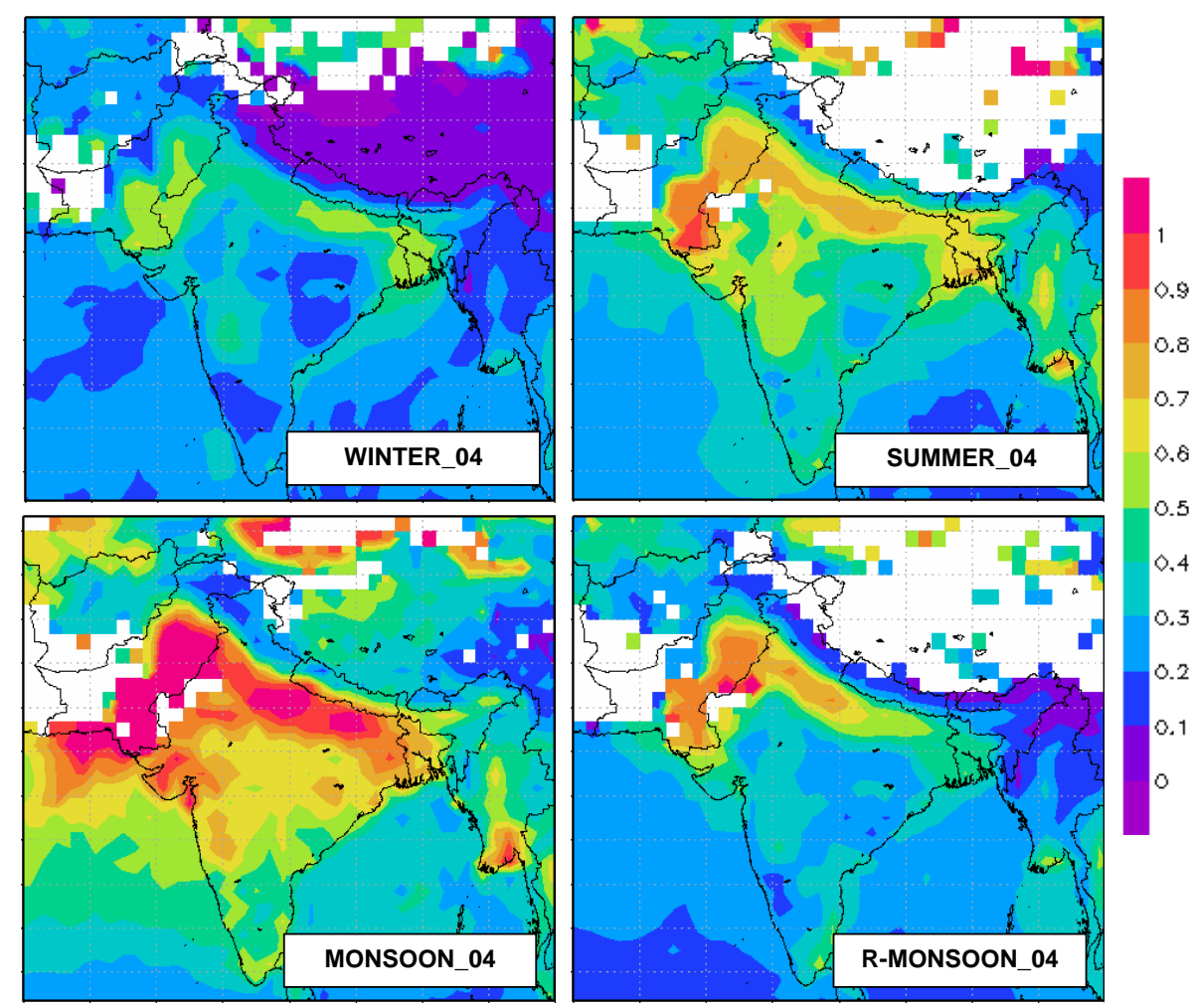

Fig. 9. Time averaged Terra aerosol optical depth at $0.55 \mu \mathrm{m}$ (Daytime) over the entire Indian zone at four representative seasons of the year 2004.

A comparison of the two sets of AODs for each month for three years during the period from January 2003 to December 2005 is shown in Fig. 7. The MWR data at $500 \mathrm{~nm}$ was discarded up to December 2002 due to malfunctioning of the filter at this wavelength. The comparison of the two sets of AOD shows a good agreement, with the values lying well within the instrumental uncertainties.

A scatter plot of MODIS derived AODs ( $\tau_{a}$ MODIS) and MWR derived AOD ( $\tau_{a}$ MWR) (Fig. 8) shows that the agreement is very good, with a mean difference of 0.027 and a root-mean square difference of 0.07 . The absolute difference between $\tau_{a}$ MODIS and $\tau_{a}$ MWR is found to be less than 0.105 .

A least-squares fit between AODs from the two estimates shows a linear relationship of the form

$\tau_{a} \mathrm{MODIS}=\tau_{a} \mathrm{MWR} \times 0.79+0.07$.

Slope lower than unity $(\sim 0.79)$ during the period of observation (Fig. 8) indicates an underestimation of AOD by MODIS with respect to MWR retrieval. The square of the correlation coefficient $\left(R^{2}\right)$ between $\tau_{a}$ MODIS and $\tau_{a}$ MWR is 0.72 .

The time-averaged MODIS derived (on board Terra platform) AODs at $550 \mathrm{~nm}$ over the Indian zone are shown in Fig. 9 for four representative seasons of the year 2004 and the seasonal mean values of AODs over Dibrugarh, derived from
MODIS (at $550 \mathrm{~nm}$ ) and MWR (at $500 \mathrm{~nm}$ and $600 \mathrm{~nm}$ ) observations during the period from December 2002 to November 2005 are given in Table 2. Examination of the values in Table 2 reveals that the AODs are higher in both the premonsoon and monsoon season during 2004 and 2005. However, the monsoon AOD is lowest during 2003. During 2004 and 2005, the lowest values of AODs are observed in the retreating monsoon season. It is interesting to note that though the distribution of aerosols over the northeastern region of India during the pre-monsoon and monsoon is similar, the total aerosol optical depth in western and coastal India is much higher in the monsoon season (AOD $>0.7$ ). Transportation of the suspended particles from these areas to northeastern India enhances the total aerosol mass loading over the MWR site.

\subsection{Influence of different airmass types on aerosol charac- teristics}

To study the impact of long-range transport of aerosols on the growth and decay of the AOD over Dibrugarh, we use the HYSPLIT model so as to trace the source and path of aerosol transport (5-day back-trajectories) for all the days on which the AOD data were available. The five-day period was considered in view of the typical residence time of $\geq 1$ week for aerosol in the lower troposphere (Ramanathan et al., 2001) 
Table 2. Seasonal mean values of MODIS $(0.55 \mu \mathrm{m})$ and MWR $(0.50 \mu \mathrm{m}$ and $0.60 \mu \mathrm{m})$ derived AOD.

\begin{tabular}{cccc}
\hline SEASONS & MODIS AOD $(0.55 \mu \mathrm{m})$ & MWR AOD $(0.50 \mu \mathrm{m})$ & MWR AOD $(0.60 \mu \mathrm{m})$ \\
\hline W-03 & $0.26 \pm 0.05$ & $0.32 \pm 0.11$ & $0.27 \pm 0.09$ \\
S-03 & $0.46 \pm 0.02$ & $0.49 \pm 0.07$ & $0.40 \pm 0.02$ \\
M1-03 & $0.23 \pm 0.09$ & $0.15 \pm 0.11$ & $0.10 \pm 0.09$ \\
M2-03 & $0.25 \pm 0.03$ & $0.22 \pm 0.02$ & $0.18 \pm 0.10$ \\
W-04 & $0.23 \pm 0.09$ & $0.20 \pm 0.10$ & $0.19 \pm 0.10$ \\
S-04 & $0.49 \pm 0.10$ & $0.44 \pm 0.11$ & $0.42 \pm 0.03$ \\
M1-04 & $0.58 \pm 0.26$ & $0.42 \pm 0.01$ & $0.42 \pm 0.01$ \\
M2-04 & $0.14 \pm 0.01$ & $0.19 \pm 0.04$ & $0.16 \pm 0.03$ \\
W-05 & $0.31 \pm 0.11$ & $0.33 \pm 0.12$ & $0.26 \pm 0.11$ \\
S-05 & $0.47 \pm 0.04$ & $0.56 \pm 0.18$ & $0.47 \pm 0.18$ \\
M1-05 & $0.44 \pm 0.09$ & $0.41 \pm 0.09$ & $0.36 \pm 0.05$ \\
M2-05 & $0.15 \pm 0.01$ & $0.21 \pm 0.06$ & $0.18 \pm 0.04$ \\
\hline
\end{tabular}

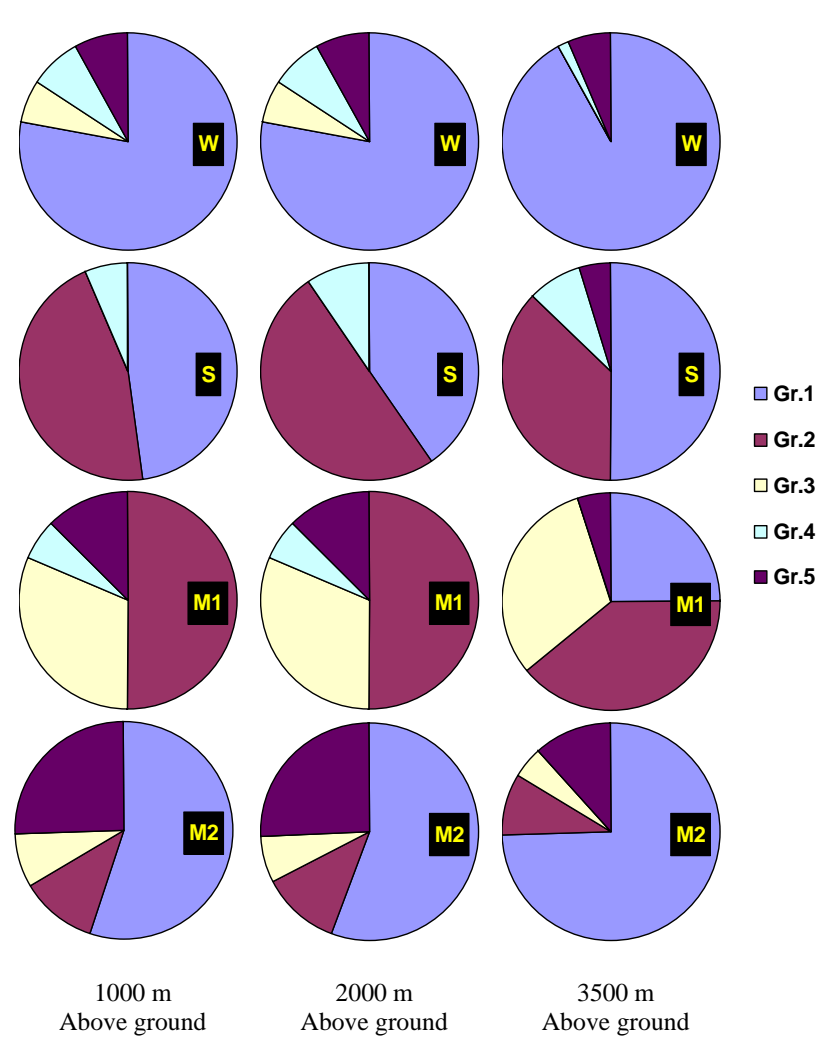

Fig. 10. Percent contribution of the different source regions to the air mass flow at Dibrugarh at 1000, 2000 and $3500 \mathrm{~m}$ above ground level.

during the dry period. As the AOD values are caused by the columnar aerosols, we considered three height levels considering the elevated topography of the northeastern region over the observation site: $1000 \mathrm{~m}$ (within Atmospheric Boundary Layer, ABL), $2000 \mathrm{~m}$ (above ABL) and $3500 \mathrm{~m}$ (in the lower free troposphere; Moorthy et al., 2003). The role of long range transport of aerosols over the Indian landmass, Chinese Himalayan region, eastern Bangladesh and Myanmar and Bay-of-Bengal (BoB) in causing changes in the optical depths, composition and physical characteristics of aerosols had been investigated and their possible implications on the variation of AOD, $\alpha$ and $\beta$ are discussed below.

The isentropic trajectories revealed significant month-tomonth variations, particularly at the lower levels. The highest free tropospheric (FT) trajectory was generally confined to the central and peninsular India. In some cases the FT trajectories originated from the west Asian countries and travelled across Pakistan and partly across the Tibetan desert region before arriving at the northeastern region, while on other occasions they originated from BoB and travelled across the northeastern landmass of India. Yet, on several days the FT trajectories were mainly confined to the boundary of northeastern India for all the 5 days.

Depending on their regional travel, the trajectories are classified into five groups. Group 1 includes the trajectories originating from west Asian regions, north and middle and the west coast of India, across the Himalayan Mountain and partly over the Tibetan desert region. In group 2, the trajectories had a significant BoB signature before reaching northeast India and then the observation point. Group 3 includes the trajectories originating from southeastern countries, such as Thailand and Myanmar. The trajectories originating from the Chinese desert region are included under group 4 . In some cases all the trajectories were confined to the boundary of northeastern India and these belong to group 5. Based on these groupings, the major airflow sectors can be divided into the (i) northwest/west sector (NW/W), (ii) southwest/south sector (SW/S), (iii) southeast/east sector (SE/E), (iv) northern sector $(\mathrm{N})$ and $(\mathrm{v})$ the local sector $(\mathrm{L})$. Trajectories were assigned to a particular sector if they resided over it for more than $80 \%$ of their traveling time before arriving Dibrugarh.

To examine the possible effect of long-range transport of aerosols, the AOD spectra, $\alpha$ and $\beta$ for each observational 
Table 3. Distribution of AOD, $\alpha$ and $\beta$ with respect to different trajectory groups.

\begin{tabular}{lclccc}
\hline Season & Group & Wind Sectors & AOD $(500 \mathrm{~nm})$ & $\alpha$ & $\beta$ \\
\hline \multirow{4}{*}{ Winter } & 1 & W & $0.33 \pm 0.20$ & $1.04 \pm 0.42$ & $0.16 \pm 0.11$ \\
& 2 & SW/S & & & \\
& 3 & E/SE & $0.15 \pm 0.06$ & $0.88 \pm 0.47$ & $0.09 \pm 0.03$ \\
& 4 & $\mathrm{~N}$ & $0.28 \pm 0.11$ & $1.01 \pm 0.19$ & $0.11 \pm 0.04$ \\
& 5 & LOCAL & $0.22 \pm 0.14$ & $0.87 \pm 0.22$ & $0.13 \pm 0.07$ \\
\hline \multirow{4}{*}{ Premonsoon Or Summer } & 1 & W & $0.49 \pm 0.25$ & $0.81 \pm 0.27$ & $0.28 \pm 0.14$ \\
& 2 & SW/S & $0.55 \pm 0.41$ & $0.73 \pm 0.49$ & $0.33 \pm 0.22$ \\
& 3 & E/SE & & & \\
& 4 & $\mathrm{~N}$ & $0.31 \pm 0.08$ & $0.64 \pm 0.09$ & $0.18 \pm 0.08$ \\
& 5 & LOCAL & & & \\
Monsoon & 1 & W & & & \\
& 2 & SW/S & $0.34 \pm 0.18$ & $0.88 \pm 0.53$ & $0.19 \pm 0.12$ \\
& 3 & E/SE & $0.13 \pm 0.08$ & $0.37 \pm 0.21$ & $0.08 \pm 0.03$ \\
& 4 & $\mathrm{~N}$ & & & \\
& 5 & LOCAL & $0.32 \pm 0.14$ & $1.14 \pm 0.36$ & $0.14 \pm 0.05$ \\
\hline \multirow{4}{*}{ R-Monsoon } & 1 & W & $0.24 \pm 0.17$ & $0.96 \pm 0.32$ & $0.11 \pm 0.08$ \\
& 2 & SW/S & $0.19 \pm 0.15$ & $0.87 \pm 0.09$ & $0.11 \pm 0.06$ \\
& 3 & E/SE & $0.16 \pm 0.02$ & $0.87 \pm 0.31$ & $0.10 \pm 0.05$ \\
& 4 & $\mathrm{~N}$ & & & \\
& 5 & LOCAL & $0.21 \pm 0.15$ & $0.92 \pm 0.27$ & $0.10 \pm 0.05$ \\
\hline
\end{tabular}

day with respect to different seasons were put into the appropriate trajectory group/sector and averaged with respect to each of them. The results are given in Table 3 and the percent contribution of each group to the air masses arriving at Dibrugarh is given in Fig. 10 in four respective seasons, irrespective of the years during the period of study at the three different atmospheric levels considered here. An example of the dominant trajectories in each of the four seasons is shown in Fig. 11.

It is seen that the transport was predominantly from the $\mathrm{NW} / \mathrm{W}$ sector at all three levels during the winter and the retreating monsoon, and the trajectories within the SW/S sector are absent Table 3 which indicates that the values of AOD and $\alpha$ are highest during this period when the trajectories belong to this sector, i.e. they are originating from west Asia, across the western continents and then pass over the Indian landmass. However, the contributions of trajectories in this sector to enhance $\beta$ are not significant. It can be seen from Fig. 9 that during the winter and retreating monsoon period, the AOD to the west of northeast India is itself not very high. As such, although the advection of anthropogenic primary and secondary aerosols from the western urban and industrial regions continues, thus cannot contribute significantly to the growth of AOD values during this period. Moreover, during October and November, the wash out by rain in the preceding months without sufficient replacement is another reason for the low AOD values and lower $\beta$ in this period. During the winter season (December and January), the aerosol produc- tion mechanism related to wind and surface conditions are weak. November and December are the driest months and January is the coldest in Dibrugarh. The values of AOD and $\alpha$ are comparatively higher in the winter with respect to those in the retreating monsoon season.

During the pre-monsoon season, the contributions from SW/S as well as NW/W sector are prominent (Fig. 10). The northern and local trajectories were absent in this season. The values of AOD and total columnar aerosol loading $\beta$ are highest during this period when the trajectories originate in the BoB (SW/S) sector. However, the highest value of $\alpha$, as well as comparable higher values of AOD and $\beta$ was obtained for the trajectories in the NW/W sector, too. The synoptic winds over Dibrugarh also show significant increase in the westerlies at upper pressure levels, except during monsoon season and the magnitude of the wind speed increases with altitude. Six representative plots at 700 and $500 \mathrm{hPa}$ (considering the elevated topography and the surrounding region) are shown in Fig. 12 for the months of March, June and December during 2004. These were obtained from the National Centre for Medium Range Weather Forecasting (NCMRWF), New Delhi. It can be seen from Fig. 9 that there are high aerosol concentration to the western and southwestern locations of Dibrugarh. Thus the highest value of $\beta$ during the pre-monsoon season indicates an increase in the loading of coarse mode particles till the onset of monsoon. Though wet removal continues during the premonsoon months, too, the change in air mass type is mostly 

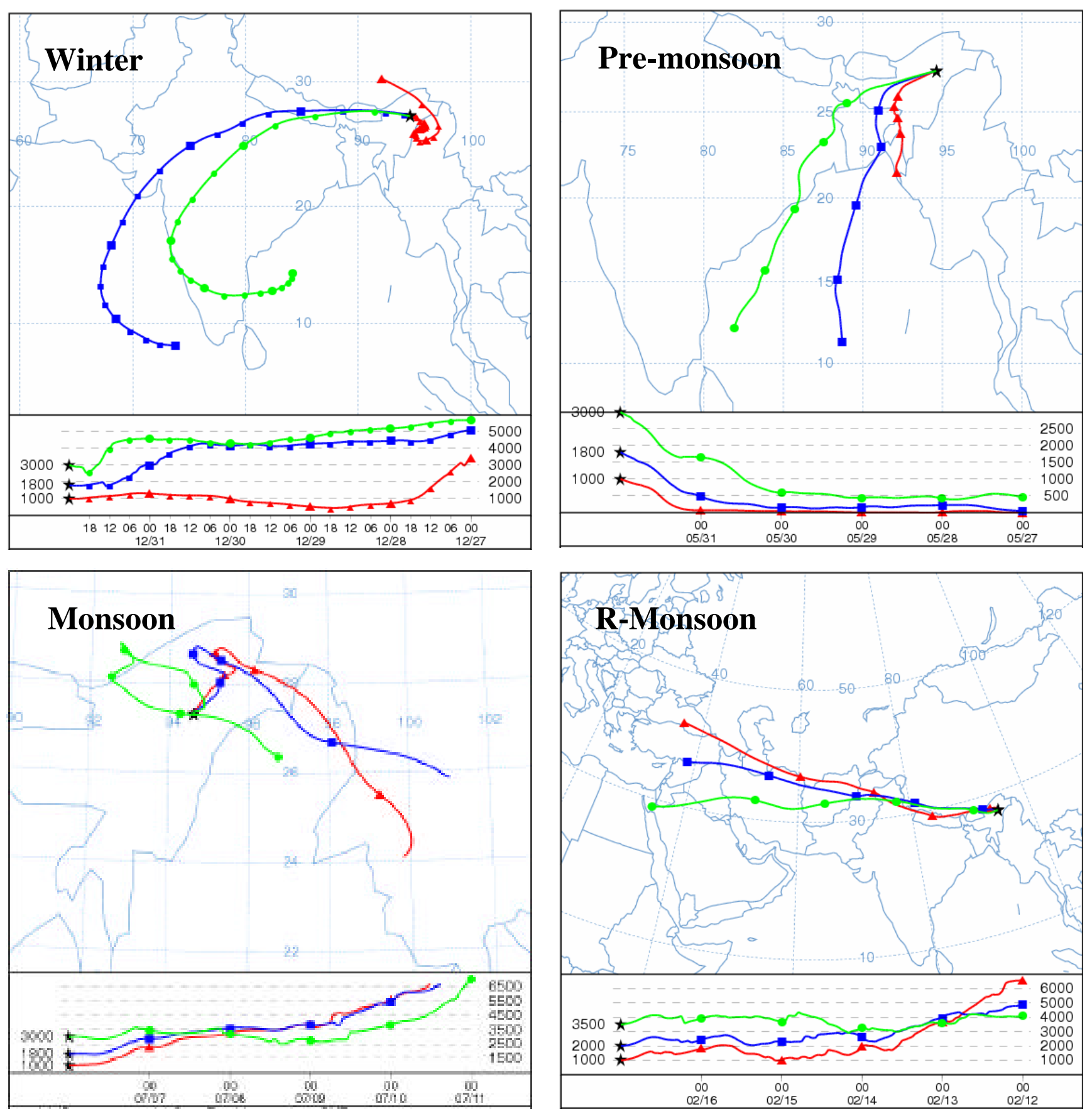

Fig. 11. Examples of five-day back trajectories at 1000, 2000 and $3500 \mathrm{~m}$ above ground level on four particular days during four different seasons: winter, pre-monsoon, monsoon and retreating-monsoon.

responsible for the rapid build up in the AOD over the station after March, as the arid air mass type is known to transport large amounts of desert and mineral aerosols from the west Asian and Indian desert, Indian mainland and BoB area. Input of aerosols (mostly coarser fraction) from Thar Desert (Fig. 1) and dry season during pre-monsoon cause high AOD (>0.6) in the Ganga basin (Prasad et al., 2004). The up- per air westerly is thus mixed with high aerosol concentration before reaching the northeastern zone of India and contributes to the growth of aerosols over this region during premonsoon season. The mineral dusts are produced over arid and semi-arid regions by the action of surface winds. Dust is a mixture of quartz and clay minerals. The long-range transport of mineral dust by the combined action of convection 
currents and general circulation systems make these particles a significant constituent even at locations far their sources. There are several literatures describing the large-scale transport of dust particles (e.g. Prospero et al., 1983; Uematsu et al., 1983; Tyson et al., 1996; Kaufman et al., 2000; Moorthy and Satheesh, 2000; Satheesh and Srinivasan, 2002).

In addition to the advection by air masses, the increased solar heating (Fig. 2) of the land mass over the lower plains adjacent to the site during the pre-monsoon season would result in increased convective mixing and elevation of the boundary layer aerosols. This also contributes to the increase in AOD over the site during the pre-monsoon season.

During monsoon, the winds are mostly from the E/SE and SW/S. As seen from Fig. 10, although high AODs are observed over the entire Indian mainland the aerosol loading over Dibrugarh appears to have remained low and unaffected by the higher content over Indian mainland. One of the various factors may be the absence of sharp trajectories from NW/W sector during the observational days. The second cause may be the occurrence of the peak in rainfall (Fig. 2) over a maximum number of rainy days. However, even when the wet removal process of aerosols continues through the entire monsoon season, the abundance of fine mode particles are considerable, as indicated by the highest value of $\alpha$ obtained under the local sector (Table 3) of trajectory analysis. Apart from this, the trajectories from BoB (SW/S sector) have contributed to the increased abundance of fine and coarse mode particles as well as to AODs. The trajectories lying within this sector reflect the higher values of $\alpha$ and $\beta$ along with the highest value of AOD during the monsoon season. It is evident from Table 3 that the trajectories in the $\mathrm{SE} / \mathrm{E}$ sector (Gr.3) have negligible contribution to the growth of AOD, $\alpha$ and $\beta$. But, as the percent occurrence of winds originating from E/SE sector is high and that from the NW/W sector is absent, it leads to a reduction in AOD during the monsoon season. Provided that the NW/W sector was a dominant one, it would have given rise to large value of AOD as well $\alpha$ and $\beta$ in the monsoon season, in spite of the persistence of heavy rainfall. This establishes the impact of longrange transport of aerosols as measured over Dibrugarh.

\section{Conclusions}

The main conclusions from the present study are the following:

1. The seasonal mean values of AODs are higher in the pre-monsoon (March, April and May) at the entire wavelength and lower in the retreating monsoon (October and November) season.

2. There is significant enhancement of aerosol optical depth at shorter wavelengths $(\lambda \leq 600 \mathrm{~nm})$ in the retreating-monsoon and winter season.
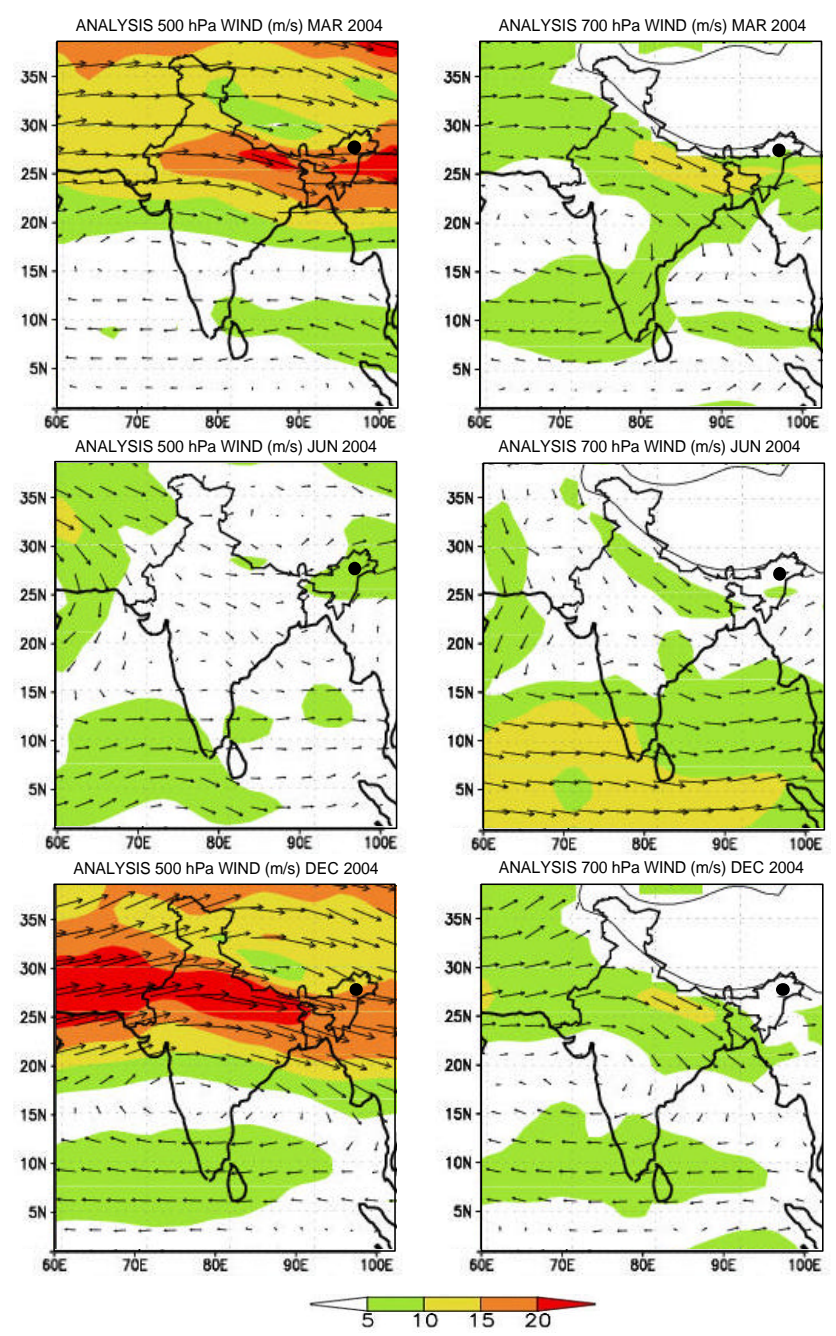

Fig. 12. Mean analysis wind pattern for the month of March, June and December at $700 \mathrm{hPa}$ and $500 \mathrm{hPa}$, as obtained from NCMRWF, New Delhi.

3. Comparison of AOD measured by MWR with the MODIS data shows very good agreement between the two, with a mean difference of 0.027 and root mean square difference of 0.07 .

4. The Ångström wavelength exponent $(\alpha)$ has a mean value of $0.56 \pm 0.07$ during monsoon, indicating a flatter aerosol size spectrum. In the winter season the value of $\alpha$ is nearly double $(0.97 \pm 0.08)$, indicating a significant enhancement of small particles attributed to be of industrial and urban origin. The synoptic upper layer winds have special contribution to the aerosol advection from the western deserts, the Gangetic plains and the BoB area.

Acknowledgements. The authors are indebted to Indian Space Research Organization for supporting this work through its GeosphereBiosphere Programme. M. M. Gogoi is grateful to ISRO-GBP for 
providing him a fellowship. We thank P. S. Pillai, SPL, VSSC, Trivandrum for her esteem help and involvement in checking the MWR data. The authors are also thankful to K. Bhuyan for critically reading the manuscript. The authors wish to acknowledge the NOAA Air Resources Laboratory (ARL), USA for the provision of the HYSPLIT transport and dispersion model used in this paper. The authors are also grateful to the National Centre for Medium Range Weather Forecasting, New Delhi for providing the wind vector maps used in this analysis. We also thank the anonymous referees for their valuable comments for improvement of the manuscript.

Topical Editor F. D'Andrea thanks two anonymous referees for their help in evaluating this paper.

\section{References}

Ångström, A.: Techniques of determining the turbidity of the atmosphere, Tellus, 13, 214-223, 1961

Bhuyan, P. K., Gogoi, M. M., and Moorthy, K. K.: Spectral and temporal characteristics of aerosol optical depth over a wet tropical location in North East India, Adv. Space Res., Elsevier, 35, 1423-1429, 2005.

Charlson, R. J., Schwartz, S. E., Heles, J. M., Cess, R. D., Coakley Jr., J. A., Hansen, J. E., and Hoffman, D. J.: Climate Forcing by Anthropogenic Aerosols, Science, 255, 423-430, 1992.

Charlson, R. J., Langner, J., Rodhe, H., Leovy, C. B., and Warren, S. G.: Perturbation of the Northern Hemesphere Radiative balance by Backscattering from Sulphate aerosols, Tellus, 43 AB, 152163, 1991.

Devara, P. C. S., Ramkumar, M., Maheskumar, R. S., and Pandithurai, G.: High-spectral resolution radiometric measurements of aerosol extinction over an urban region in India, Meas. Sci. Technol, 12, 691-697, 2001.

Draxler, R. R. and Hess, G. D.: Description of the Hysplit_4 modelling system, NOAA Tech. Memo. ERL ARL-224, 24, Natl. Oceanic and Atmos. Admin., Washington, D.C., 1997.

Formenti, P., Andreae, M. O., Andreae, T. W., Galani, E., Vasaras, A., Zerefos, C., Amridis, V., Orlovsky, L., Karnieli, A., Wendisch, M., Wex, H., Holben, B. N., Maenhaut, W., and Lelieveld, J.: Aerosol optical properties and large-scale transport of air masses: Observations at a coastal and a semiarid site in the eastern Mediterranean during summer 1998, 106(D9), 98079826, 2001.

Gutiërrez-Moreno, A. and Cortës, G.: A study of atmospheric extinction at Cerro Tololo Inter-American observatory, Publ. Astron. Soc. Pac., 94, 722-728, 1982.

Jayaraman, A. and Subbaraya, B. H.: In situ measurements of aerosol concentration profiles and their spectral dependencies at tropospheric levels, Tellus, 45B, 473-478, 1993.

Junge, C. E.: Air Chemistry and Radioactivity, Academic, NY, 1963.

Kaufman, Y. J., Ichoku, C., Giglio, L., Korontzi, S., Chu, D. A., Hao, W. M., Li, R. R., and Justice, C. O.: Fire and smoke observed from the Earth Observing System MODIS instrument: Products, validation, and operational use, Int. J. Remote. Sens., 24(8), 1765-1781, 2003.

Kaufman, Y. J., Karnieli, A., and Tenre, D.: Detention of dust over deserts using satellite data in the solar wavelengths, IEEE Trans. Geosci. Remote Sensing, 38, 525-531, Part 2, 2000.
King, M. D.: Sensitivity of constrained linear inversion to the selection of Lagrange multiplier, J. Atmos. Sci., 39, 1356-1369, 1982.

Leckner, B.: The spectral distribution of solar radiation at the earth's surface-elements of a model, Sol. Energy, 20, 143-150, 1978

Moorthy, K. K. and Satheesh, S. K.: Characteristics of aerosols over a remote island, Minicoy in the Arabian Sea, Optical properties and retrieved size characteristics, Q. J. Roy. Meteorol. Soc., 126, 81-109, 2000.

Moorthy, K. K., Niranjan, K., Narasimhamurthy, B., Agashe, V. V., and Murthy, B. V. K.: Aerosol climatology over India: ISRO GBP MWR network and database, ISRO GBP SR-03-99, Indian Space Res. Organ., Bangalore, 1999.

Moorthy, K. K., Saha, A., Prasad, B. S. N., Niranjan, K., Jhurry, D., and Pillai, P. S.: Aerosol optical depth over peninsular India and adjoining oceans during the INDOEX campaigns: spatial, temporal and spectral characteristics, J. Geophys. Res., 106, 28 539-28 554, 2001

Moorthy, K. K., Nair, P. R., and Krishna Murthy, B. V.: Sea-breeze front effects on boundary layer aerosols at a tropical coastal station, J. Appl. Meteor., 32, 1196-1205, 1993.

Moorthy, K. K., Nair, P. R., and Krishna Murthy, B. V.: A study on aerosol optical depth at a coastal station, Trivandrum, Indian J. Radio Space Phys., 17, 16-22, 1988.

Moorthy, K. K., Nair, P. R., and Krishna Murthy, B. V.: Multiwavelength solar radiometer network and features of aerosols optical depth at Trivandrum, Ind. J. Radio Space Phys., 18, 194-201, 1989.

Moorthy, K. K., Nair, P. R., and Krishna Murthy, B. V.: Size distribution of coastal aerosols; effects of local sources and sinks, J. Appl. Meteor., 30, 844-852, 1991

Moorthy, K. K., Satheesh, S. K., and Murthy, B. V. K.: Investigations of marine aerosols over tropical Indian Ocean, J. Geophys. Res., 102, 18 827-18 842, 1997.

Moorthy, K. K., Satheesh, S. K., and Krishna Murthy, B. V.: Characteristics of spectral optical depths and size distributions of aerosols over tropical oceanic regions, J. Atmos. Sol. Terr. Phy., 60, 981-992, 1998.

Moorthy, K. K., Sunilkumar, S. V., Pillai, P. S., Parameswaran, K., Nair, P. R., Ahmed, Y. N., Ramgopal, K., Narasimhulu, K., Reddy, R. R., Vinoj, V., Satheesh, S. K., Niranjan, K., Rao, B. M., Brahmanandam, P. S., Saha, A., Badarinath, K. V. S., Kiranchand, T. R., and Madhavi Latha, K.: Wintertime spatial characteristics of boundary layer aerosols over peninsular India, J. Geophys. Res., 110, D08207, doi:10.1029/2004JD005520, 2005.

Moorthy, K. K., Suresh Babu, S., and Satheesh, S. K.: Aerosol spectral optical depths over the Bay of Bengal: Role of transport, Geophys. Res. Lett., 30(5), 1249, doi:10.1029/2002GL016520, 2003.

Nair, P. R. and Moorthy, K. K.: Effects of changes in atmospheric water vapor content on physical properties of atmospheric aerosols at a coastal station, J. Atmos. Sol. Terr. Phy., 60, 563-572, 1998.

Niranjan, K., Rao, B. M., Saha, A., and Murty, K. S. R.: Aerosol spectral optical depths and size characteristics at a coastal industrial location in India-effect of synoptic and mesoscale weather, Ann. Geophys., 22, 1851-1860, 2004, http://www.ann-geophys.net/22/1851/2004/. 
Prasad, A. K., Singh, R. P., and Singh, A.: Variability of aerosol optical depth over Indian subcontinent using MODIS data, J. Ind. Soc. Rem. Sensing, 32(4), 313-316, 2004.

Prospero, J. M., Charlson, R. J., Mohnen, B., Jaenicke, R., Delany, A. C., Mayers, J., Zoller, W., and Rahn, K.: The atmospheric aerosol system-an overview, Rev. Geophys. Res., 99, 16771$16778,1983$.

Ramanathan, V., Crutzen, P. J., Lelieveld, J., Mira, A. P., Althausen, D., Andersen, J., Andreae, M. O., Cantrell, W., Cass, G. R., Chung, C. E., Clarke, A. D., Coalkey, J. A., Collins, W. D., Conant, W. C., Dulac, F., Heinzenberg, J., Heymsfield, A. J., Holben, B., Howell, S., Hudson, J., Jayaraman, A., Kiehl, J. T., Krishnamurti, T. N., Lubin, D., McFarquhar, G., Novakov, T., Ogren, J. A., Prodigy, I. A., Prather, K., Priestly, K., Prospero, J. M., Quinn, P. K., Rajeev, K., Rasch, P., Rupert, S., Sadourny, R., Satheesh, S. K., Shaw, G. E., Sheridan, P., Valero, F. P. J.: Indian Ocean Experiment: An integrated analysis of the climate forcing and effects of the great Indo-Asian haze, J. Geophys. Res., 106, 28 371-28 398, 2001.

Russell, P. B., Livingston, J. M., Dutton, E. G., Pueschel, V., Reagon, J. A., Defoor, T. E., Box, M. A., Allen, D., Pilewskie, P., Herman, B. M., Kinnie, S. A., and Hofmann, D. J.: Pinatubo and pre-pinatubo optical depth spectra: Mauna Loa measurements, comparisons, inferred particle size distribution, radiative effects and relationship to Lidar data, J. Geophys. Res., 98, 22969 $22985,1993$.

Sagar. R., Kumar, B., Dumca, U. C., Krishna Moorthy, K., and Pant, P.: Characteristics of aerosol optical depths over Manora Peak; A High altitude station in the central Himalaya, Journal of Geophys. Res., 109, 006207, doi:10.1029/2003JD003954, 2004.

Saha, A. and Moorthy, K. K.: Impact of precipitation on aerosol spectral optical depth and retrieved size distributions: a case study, J. Appl. Met., 43(6), 902-914, 2004.

Saha, A. and Moorthy, K. K.: Interannual variations of aerosol optical depth over coastal India: relation to synoptic meteorology, J. Appl. Met., 44, 1066-1077, 2005.

Sasi, M. N. and Sen Gupta, K.: Science Report ISRO:VSSC:SR:19:72, Vikram Sarabhai Space Centre, Trivandrum, 1979.

Satheesh, S. K. and Moorthy, K. K.: Aerosol characteristics over coastal regions of the Arabian sea, Tellus, 49 B, 417-428, 1997.

Satheesh, S. K. and Srinivasan, J.: Enhanced aerosol loading over Arabian Sea during pre-monsoon season: Natural or anthropogenic, Geophys. Res. Lett., 29, 1874, doi:10.1029/2002GL015687, 2002.

Satheesh, S. K., Moorthy, K. K., and Das, I.: Aerosol spectral optical depths over the Bay of Bengal, Arabian Sea and Indian Ocean, Current Science, 81(12), 1617-1624, 2001.
Satheesh, S. K., Ramanathan, V., Jones, X. L., Lobert, J. M., Podgorny, I. A., Prospero, J. M., Holben, B. N., and Loeb, N. G.: A model for the natural and anthropogenic aerosols for the tropical Indian Ocean derived from the INDOEX data, J. Geophys. Res., 104(D22), 27 421-27 440, 1999.

Sharma, D. K., Rai, J., Israil, M., and Singh, P.: Summer variations of the atmospheric aerosol number concentration over Roorkee, India, J. Atmos. Sol. Terr. Phys., 65, 1007-1019, 2003.

Shaw, G. E., Reagen, J. A., and Herman, B. M.: Investigations of atmospheric extinctions using direct solar radiation measurements made with a multiple wavelength radiometer, J. Appl. Met., 12, 374-380, 1973.

Smirnov, A., Royer, A., O'Neill, N. T., and Tarussov, A.: A study of the link between synoptic airmass type and atmospheric optical parameters, J. Geophys. Res., 99, 20 967-20 982, 1994.

Suresh, T. and Desa, E.: Seasonal variation of aerosol over Dona Paula, a coastal site on the west coast of India, Atmos. Environ., 39, 3471-3480, 2005.

Suzuki, T. and Tsunogai, S.: Daily variation of aerosols of marine and continental origin in the surface air over a small island Okushin in Japan Sea, Tellus, 40B, 42-49, 1988.

Tomasi, C., Prodi, F., Sentimenti, M., and Cesari, G.: Multiwavelength sun photometers for accurate measurements of atmospheric extinction in the visible and near-IR spectral range, Appl. Opt., 22, 622-630, 1983.

Tomasi, C., Marani, S., and Vitale, V.: Multiwavelength sunphotometer calibration corrected on the basis of the spectral features characterizing particulate extinction and nitrogen dioxide absorption, Appl. Opt., 24, 2962-2970, 1985.

Tripathi, S. N., Dey, S., Chandel, A., Srivastava, S., Singh, R. P., and Holben, B. N.: Comparison of MODIS and AERONET derived aerosol optical depth over the Ganga Basin, India, Ann. Geophys., 23, 1093-1101, 2005, http://www.ann-geophys.net/23/1093/2005/.

Tyson, P. D., Garstang, M., Swap, R., Kallberg, P., and Edwards, N.: An air transport climatology for subtropical southern Africa, Int. J. Climatol., 16, 256-291, 1996.

Uematsu, M., Duce, R. A., Prospero, J. M., Chen, L., Merrill, J. T., and Mcdonald, R. L.: Transport of mineral aerosols from Asia over the north Pacific Ocean, J. Geophys. Res., 88, 5343-5352, 1983.

Vinoj, V., Babu, S. S., Satheesh, S. K., Moorthy, K. K., and Kaufman, Y. J.: Radiative forcing by aerosols over the Bay of Bengal region derived from shipborne, island-based and satellite (Moderate Resolution Imaging Spectroradiometer) observations, J. Geophys. Res., 109, D05203, doi:10.1029/2003JD004329, 2004. 